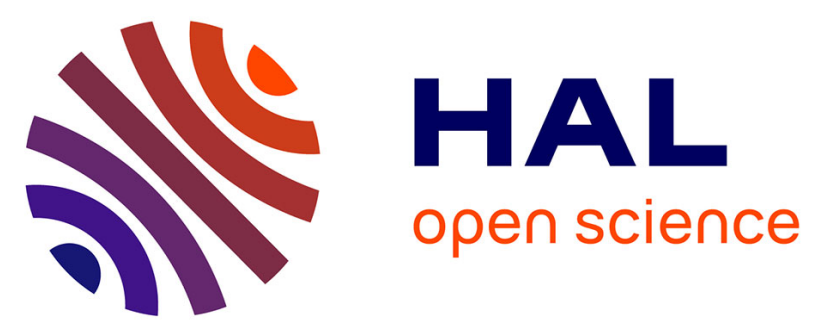

\title{
ROBUST GAN ELECTRONICS FOR HIGHLY RELIABLE BF AND RF ANALOG SYSTEMS IN AEROSPACE APPLICATIONS
}

Geoffroy Soubercaze-Pun, Jean-Guy Tartarin, Laurent Bary, Jacques Rayssac, S Delage, Jacques Graffeuil

\section{To cite this version:}

Geoffroy Soubercaze-Pun, Jean-Guy Tartarin, Laurent Bary, Jacques Rayssac, S Delage, et al.. ROBUST GAN ELECTRONICS FOR HIGHLY RELIABLE BF AND RF ANALOG SYSTEMS IN AEROSPACE APPLICATIONS. Micro-Nano-Technologies for Space Application (CANEUS 2006), Aug 2006, Toulouse, France. pp.81-87, 10.1115/CANEUS2006-11012 . hal-01343284

\section{HAL Id: hal-01343284 \\ https://hal.science/hal-01343284}

Submitted on 8 Jul 2016

HAL is a multi-disciplinary open access archive for the deposit and dissemination of scientific research documents, whether they are published or not. The documents may come from teaching and research institutions in France or abroad, or from public or private research centers.
L'archive ouverte pluridisciplinaire HAL, est destinée au dépôt et à la diffusion de documents scientifiques de niveau recherche, publiés ou non, émanant des établissements d'enseignement et de recherche français ou étrangers, des laboratoires publics ou privés. 


\title{
CANEUS2006-11012
}

\section{ROBUST GAN ELECTRONICS FOR HIGHLY RELIABLE BF AND RF ANALOG SYSTEMS IN AEROSPACE APPLICATIONS}

\author{
G. Soubercaze-Pun ${ }^{1,2}$, J.G Tartarin ${ }^{1,2}$, L. Bary ${ }^{1}$, J. Rayssac ${ }^{1}$, S. Delage ${ }^{3}$,G. Graffeuil ${ }^{1,2}$ \\ ${ }^{1}$ LAAS-CNRS and ${ }^{2}$ Paul Sabatier University, \\ 7 av. du Colonel Roche, 31007 Toulouse cedex 4, France \\ ${ }^{3}$ TIGER, Alcatel-Thales III-V Lab, Route de Nozay, 91460 Marcoussis, France
}

\begin{abstract}
The reliability and robustness of electronic sub-systems dedicated to control and communications in the aerospace sector is more than ever one of the key points for safety and security, essentially during landing operations. As aircraft manufacturers have to diversify their mean of communication system's control (Full-Duplex and System), the reliability can be improved both by setting redundant remote networks, and also by using matched technologies for increased performances and robustness: the wide band-gap Gallium Nitride technology $(\mathrm{GaN})$ newly developed fits perfectly to the requirements of systems such as Microwave Landing System (MLS) or Distance Measuring Equipments (DME) used during the final landing approach. Actually, GaN technology takes advantage of a natural immunity to electromagnetic perturbations, and is suitable for circuit design in the RF frequency band (up to 5 $\mathrm{GHz}$ for aircraft applications). The GaN based circuits are able to improve transceiver's efficiency (and so the radio-link budget) thanks to their low noise figure (receiver) and high output power (transmitter), reducing digital bit error rate during the code demodulation. This point is crucial while electronic runs in an urban environment. Moreover, the next electronic systems developed for "composite aircraft" will be more exposed to high electric field and CEM problems in circuits.

Furthermore, this GaN integrated technology allows a reduction of volume for transmitter's sub-systems, and is easy to setup (aircraft maintenance): the risk of immobilisation during the aircraft exploitation will be reduced and his maintainability will be easier. Finally, this technology is also perfectly suited for ground navigation control systems such as radar.
\end{abstract}

This work presents the challenge for civil and military future avionic systems by making use of $\mathrm{GaN}$ based technologies.

\section{INTRODUCTION}

A growing number of semiconductor technologies such as silicon LDMOS, silicon germanium HBT, gallium arsenide MESFET, aluminum gallium arsenide pHEMT or silicon carbide MESFET are matched for radiofrequency power applications. But a new robust technology is emerging on this market: Gallium Nitride High Electron Mobility Transistor (AlGaN/GaN HEMT) fits the high frequency applications requirements, thanks to a wide band gap (for improved robustness to electromagnetic perturbations / aggressions) and low noise (receiver's low signal detection) that is essential for telecommunication's electronic sub-systems.

GaN technology will use for RADAR applications (Military), power Telecommunications (Base transceiver stations) and power switching (Aeronautic). Moreover, its range of applications is very large due to its intrinsic material properties and the two substrates for $\mathrm{GaN}$ growing. Silicon carbide substrate is dedicated for military applications whereas the Silicon substrate is dedicated for the low cost applications. In addition, companies work to reduce the cost of HEMT devices with larger semi insulating substrate (4-inch). The new substrate targets the telecommunications market. The aim is to reduce the price around $1 \$ /$ Watt to be able to break the silicon LDMOS monopole.

This article focuses on sub systems by making use of GaN based technologies that could be at the root of future complex avionic systems.

The maturity and structural defects of this new technology is evaluated thanks to low frequency noise measurements. 
Electrical performances are exposed to clearly evidence why $\mathrm{GaN}$ is a competitive technology for high power, high frequency robust systems. Some circuits are thus presented to evidence high performances that can be obtained: an X-band oscillator has been realised using Thales TRT Tiger HEMT process, with state of the art performances.

\section{GAN HEMT DIE}

The device reliability and robustness is a crucial characteristic for the increasing needs on operating life in aeronautic electronics sub-systems. Aircraft manufacturers are looking for electronics systems that doesn't need any maintenance and with a very low risk of breakdown during the aircraft exploitation. The aim is to reduce the aircraft standstill.

\section{What is AlGaN/GaN HEMT?}

The High Electron Mobility Transistor (HEMT) processed by Thales TRT in gallium nitride ( $\mathrm{GaN}$ ) grown by MOCVD (Metal Organic Chemical Vapor Deposition) feature excellent characteristics for high frequency and robust applications. The $\mathrm{GaN}$ material properties perfectly fit the requirements of high power microwave applications (Solid State Power Amplifiers SSPA substituting to Traveling Wave Tubes TWT amplifiers) and other kind of electronic applications.

The figure 1 shows a cross section view of the $\mathrm{AlGaN} / \mathrm{GaN}$ HEMT device.

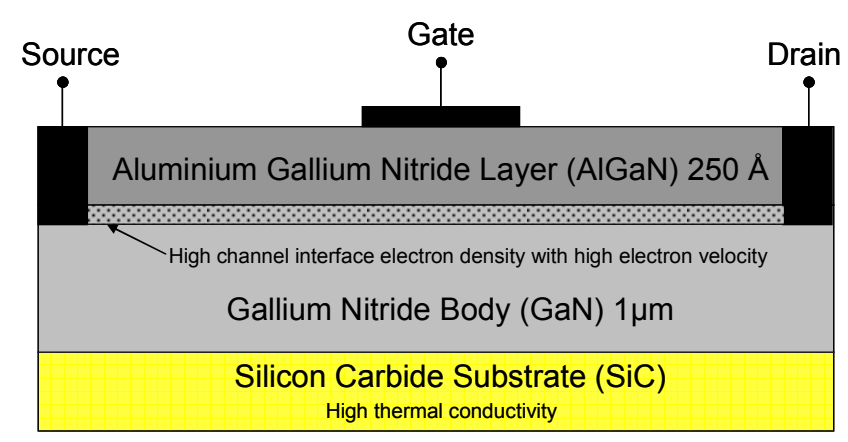

Figure 1: Schematic cross section of AlGaN/GaN HEMT die

One particularity of this technology stems from the fact that the device can be grown using several different substrates. This choice offers a large variety of components which preserves the properties of gallium nitride $(\mathrm{GaN})$, but with various prices and performances, thus dedicated to different applications according to the substrate.

-Silicon substrate ( $\mathrm{Si}$ ), it is a low cost substrate with high production volume on the electronic market. But the lattice mismatch between silicon and gallium nitride causes cracks in the structure, and degrades the electrics performances of the device such as the low frequency noise (that is up-converted into phase noise for high spectral purity oscillators) and then reduces the device's intrinsic operating life.

-Sapphire substrate $\left(\mathrm{Al}_{2} \mathrm{O}_{3}\right)$ has a best lattice agreement with the gallium nitride, but the poor thermal conductivity is not matched for high power applications.

-Silicon carbide substrate $(\mathrm{SiC})$ is the most interesting substrate for this type of technology. Its lattice length is close to that of the gallium nitride, so the presence of cracks in the devices is less important. The SiC thermal conductivity is excellent and offers a good thermal evacuation. The technological process developed by TIGER is described in [1]. A good manufacturing yield and homogeneity of the electrical performances is noticed over the wafer, with less than $15 \%$ dispersion on the main electrical parameters.

\section{Why GaN technology for aerospace applications?}

For aerospace applications, the main features are good immunity against electromagnetic aggression and device robustness against electric choc. The gallium nitride components offer high band-gap energy $\left(\mathrm{E}_{\mathrm{G}}\right)$. This band-gap is three times higher than that of the silicon. This fundamental intrinsic characteristic gives to this technology a high breakdown voltage close to $5 \mathrm{MV} / \mathrm{cm}$.

Thus, gallium nitride components stand as interesting devices for aerospace transmitter's sub-systems.

The table 1 shows a comparison between different technologies.

\begin{tabular}{|c|c|c|c|c|}
\cline { 2 - 5 } \multicolumn{1}{c|}{} & \multicolumn{2}{c|}{ Usual Technologies } & \multicolumn{2}{c|}{ New Technologies } \\
\cline { 2 - 5 } \multicolumn{1}{c|}{} & $\mathrm{Si}$ & $\mathrm{GaAs}$ & $\mathrm{SiC}$ & $\mathrm{GaN}$ \\
\hline $\mathrm{Eg}[\mathrm{eV}]$ & 1.12 & 1.42 & $\mathbf{3 . 2 3}$ & $\mathbf{3 . 4}$ \\
\hline$\lambda\left[\mathrm{Wcm}{ }^{-1}{ }^{\circ} \mathrm{C}\right]$ & 1.5 & 0.5 & $\mathbf{4 . 5}$ & 1.3 \\
\hline $\mathrm{E}[\mathrm{V} / \mathrm{cm}]$ & $5 * 10^{5}$ & $7 * 10^{5}$ & $\mathbf{3 . 5}^{*} \mathbf{1 0}^{\mathbf{6}}$ & $\mathbf{5}^{*} \mathbf{1 0}^{\mathbf{6}}$ \\
\hline
\end{tabular}

Table 1: Comparison between usual technologies and wide bandgap technologies

Other intrinsic properties of GaN material can be noticed, such as the high channel temperatures (up to $500 \mathrm{~K}$ ). This feature allows the $\mathrm{GaN}$ devices to work in hard environment. In comparison with the GaAs III-V technology, the robustness of $\mathrm{AlGaN} / \mathrm{GaN}$ HEMT is found to be 20 times better.

The long term storage is strategic for aerospace industry. To secure supplying during the aircraft life and maintenance, the transistors must be able to endure long term storage. The excellent chemical and metallurgical stability of $\mathrm{GaN}$ devices allow long term strategic procurement. Moreover, the aeronautic industry depends on electronic components and needs to respond to the problem of component obsolescence. The GaN is a new wide band gap technology which will be less obedient to process evolution as classic technology due to its natural high intrinsic performances. 
The electron velocity is also fundamental for high frequency applications such as RADAR or MLS systems. The high electron mobility peak at $2.7 \mathrm{~cm} / \mathrm{s}$ of these devices offers high transition frequency $\left(\mathrm{f}_{\mathrm{T}}=110 \mathrm{GHz}\right)$. Furthermore the high density of electrons in the structure provides high power densities (some $10 \mathrm{~W} / \mathrm{mm}$ at $10 \mathrm{GHz}$ ) that have been achieved by several laboratories.

The figure 2 sums up the range of applications where GaN technologies should be employed for its high reliability and robustness.

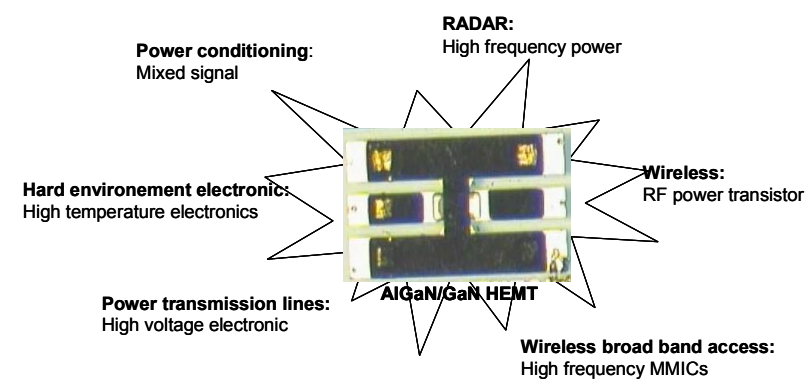

Figure 2: GaN HEMT range of applications

\section{GAN SUB-SYSTEMS}

This section presents microwave sub-systems making use of GaN technology. Next are presented different circuits such as a power amplifier, a low noise amplifier and an oscillator in $\mathrm{X}$ band frequency. These one can be used in aerospace applications ( $\mathrm{X}$ band radar transponder, $\mathrm{X}$ band low noise amplifier or in the microwave landing system (MLS)). Then, the final paragraph deals with power GaN HEMT which can also be used in aerospace applications.

\section{Power Amplifier}

$\mathrm{GaN}$ power amplifier on $\mathrm{SiC}$ substrate in MMIC (Monolithic Microwave Integrated Circuit) is suitable for phase array radar in X-band for aerospace applications. This has been demonstrated with a dual-stage GaN power amplifier design that supplies $18 \mathrm{~dB}$ of gain at $8.5 \mathrm{GHz}$ with a pulsed output power of $9 \mathrm{~W}$ with a reduced chip size [2]. The compression point $\mathrm{P}_{1 \mathrm{~dB}}$ is evaluated close to $25 \mathrm{dBm}$. The advantage of this technology is the high power density of GaN and the good thermal management with the $\mathrm{SiC}$ substrate that provides a good behavior even when temperature increases.

The figure 3 shows an AlGaN/GaN HEMT power amplifier also available as a COTS (Components Off The Shelf).

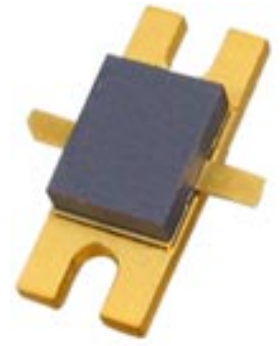

Figure 3: Example of a $37 \mathrm{~W}$ packaged GaN HEMT featuring $40 \%$ power added efficiency, frequency range 300-5000 MHz [3].

\section{Low Noise Amplifier}

GaN HEMT is also an excellent candidate for low noise applications in transceiver's sub-system. The low noise figure associated with high breakdown voltages make possible to cancel the limiter before the amplifier stage. Thus the limiter doesn't degrade the overall noise figure of the receiver, and the radio link budget can be improved. For instance, a two stage amplifier [4] presents a $1.81 \mathrm{~dB}$ noise figure at $10 \mathrm{GHz}$ and $18 \mathrm{~dB}$ small signal gain. The compression point $\mathrm{P}_{1 \mathrm{~dB}}$ is measured at $22 \mathrm{dBm}$. The chip size is as small as $1.5 * 2.5 \mathrm{~mm}^{2}$. Moreover, the compression point is $40 \mathrm{~dB}$ higher than for usual low noise amplifiers used in aeronautic commercial technologies, and meets condition of noise figure lower than $2 \mathrm{~dB}$. All theses performances are interesting to reduce bit error rate during communications and to decrease the volume and the weight of equipments. Low noise amplifiers have been designed by Thales and Alcatel Alenia Space fitting these requirements.

\section{Low Noise Oscillator}

GaN HEMT provided by Thales TRT can be used for hybrid $\mathrm{X}$ band low phase noise oscillators [5]. We have designed a $10 \mathrm{GHz}$ oscillator featuring an output power measured at $20 \mathrm{dBm}$, and a phase noise measured at $105 \mathrm{dBc} / \mathrm{Hz}$ at $100 \mathrm{kHz}$ from the carrier. Thus GaN HEMTs can be employed to simultaneously achieve high power and low noise performances in a single circuit. The pushing and pulling factors are evaluated at $13 \mathrm{MHz} / \mathrm{V}$ and $130 \mathrm{MHz}$ respectively, without any buffer stage.

This MIC design (Microwave Integrated Circuit) proves that this technology is also compatible with on-board technology. Using GaN technology, the CEM design of the electronic board is easier.

\section{Microwave Landing System}

All these sub systems (power amplifier, low noise amplifier, loxw noise oscillator) can be used for a robust system design (MLS in commercial aircraft). The risk of breakdown during critical phases of flight like the landing approach should 
be reduced: the current technology used for the MLS range of frequency $(5 \mathrm{GHz})$ makes use of gallium arsenide (GaAs), which is much more sensitive to electromagnetic aggressions. This point is usually palliated thanks to specific and complex designs, whereas the natural immunity of GaN technology to electromagnetic discharge both reduces the design complexity and improves the reliability.

\section{Power Applications}

Aerospace industry needs switching power devices for high current applications. The transistors used for the switch demand a specific on-resistance, a high breakdown voltage and a high temperature operation. GaN technology can supply a drain current over $30 \mathrm{~A}$ in high temperature operation over $300^{\circ} \mathrm{C}$ [6]. For these reasons, the GaN HEMT is also an excellent component for power uses as DC/DC converter for motor and generator.

\section{GAN MATURITY EVALUATED BY LOW FREQUENCY NOISE}

In the next section, the study relates to the technological maturity level of the GaN devices. The low frequency noise (LFN) measurement can be used as an indicator of the technological maturity. The device reliability can be also assessed with LFN characterization.

Another issue for low frequency noise measurements concerns the design of low phase noise circuits (essentially oscillators). The LFN characteristic is up-converted (in non-linear devices such as oscillators or mixers) around the carrier. This parameter is thus one of the key points for stable frequency synthesis to avoid the degeneration of the performances of the electronic sub-system.

\section{Noise experimental workbench}

The noise experimental setup used for the measurements is based on the trans-impedance amplifier direct measurement technique which allows rapid LFN measurements from $1 \mathrm{~Hz}$ to $1 \mathrm{MHz}$ : spectral densities measurements of $\mathrm{S}_{\mathrm{ID}}$ (Drain), $\mathrm{S}_{\mathrm{IG}}$ (Gate) and cross-correlation $\mathrm{S}_{\mathrm{IDIG}}$ can be performed simultaneously. Special care has been given to the workbench configuration to avoid any disturbance from gate to drain while measuring $\mathrm{S}_{\mathrm{ID}}$, and from drain to gate while measuring $\mathrm{S}_{\mathrm{IG}}$.

The figure 4 shows the bench.

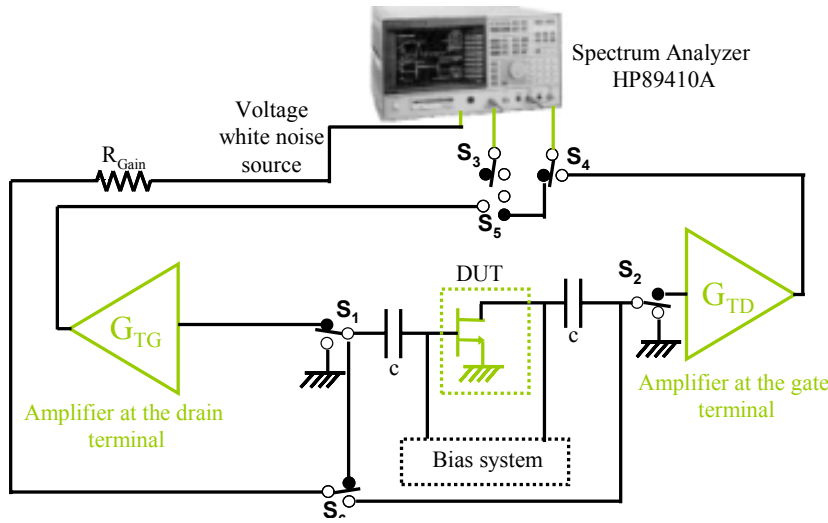

Figure 4: LAAS-CNRS low frequency noise experimental steup.

\section{A figure of merit for technological comparison}

The Hooge parameter $\left(\alpha_{\mathrm{H}}\right)$ is a figure of merit that allows technological comparisons between field effect transistors. This parameter allows the comparison between silicon, gallium arsenide or gallium nitride technology, and sort out the best devices according to the required specifications.

The $\alpha_{H}$ parameter is obtained using Peransin's technique [7] (figure 5).

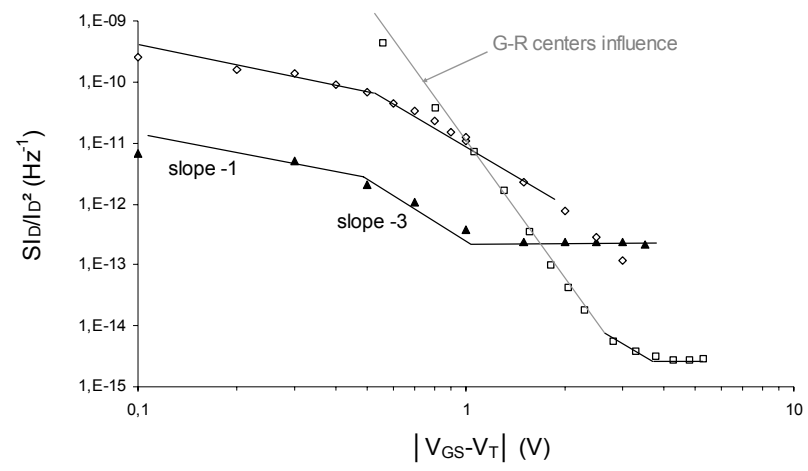

Figure 5: LFN under Ohmic operating mode, Peransin technique applied to AlGaN/GaN HEMT featuring $0.15 \times 2 \times 50 \mu m^{2}: \triangle \mathrm{Al}_{2} \mathrm{O}_{3}, \square \mathrm{SiC}, \diamond \mathrm{Si}$ substrates

In this paper, the choice of the technology for an oscillator demonstrator is carried out between HEMT grown on three different substrates. For example, a maximum value of $\alpha_{\mathrm{H}} \approx 5.10$ 5 is found for our AlGaN/GaN HEMTs grown on $\mathrm{SiC}$ substrate, close to state of the art performances for the best technologies. This figure of merit for devices on $\mathrm{SiC}$ substrate is better compared with measurement of devices grown on sapphire and silicon substrates (resp. $\alpha_{\mathrm{H}}=1.10^{-4}$ and $\alpha_{\mathrm{H}}=5 \cdot 10^{-3}$ ).

The table 2 presents Hooge parameter's values reported for AlGaN/GaN HEMT grown on sapphire and silicon carbide substrates. 


\begin{tabular}{|c|c|c|c|}
\hline \multicolumn{2}{|c|}{ Sapphire substrate } & \multicolumn{2}{c|}{ Silicon Carbide Substrate } \\
\hline$\alpha_{\mathrm{H}}=1 * 10^{-4}$ & {$[8]$} & $\alpha_{\mathrm{H}}=1 * 10^{-4}$ & {$[11]$} \\
\hline$\alpha_{\mathrm{H}}=2 * 10^{-4}$ & {$[9]$} & $\alpha_{\mathrm{H}}=4 * 10^{-4}$ & {$[12]$} \\
\hline$\alpha_{\mathrm{H}}=1 * 10^{-5}$ & {$[10]$} & $\alpha_{\mathrm{H}}=2.7 * 10^{-5}$ & {$[13]$} \\
\hline
\end{tabular}

\section{Table 2: Comparison of Hooge parameters between sapphire and silicon carbide substrate.}

\section{Evaluation of robustness}

Using Peransin's technique presented in the figure 5, it is also possible to get indications about the quality of the ohmic contacts (one of the main failure location). The comparison of the level for the "slope 0 " indicates a good process maturity for component growth on $\mathrm{SiC}$ substrate. The high temperature running conditions for these devices should involve metal migration on the contacts, that's why a good process mastering is crucial.

\section{Low frequency noise for oscillator's design}

The low frequency noise (LFN) behavior under saturated bias conditions is closely related to the phase noise of the oscillator.

The figure 6 shows a low frequency drain noise current spectrum.

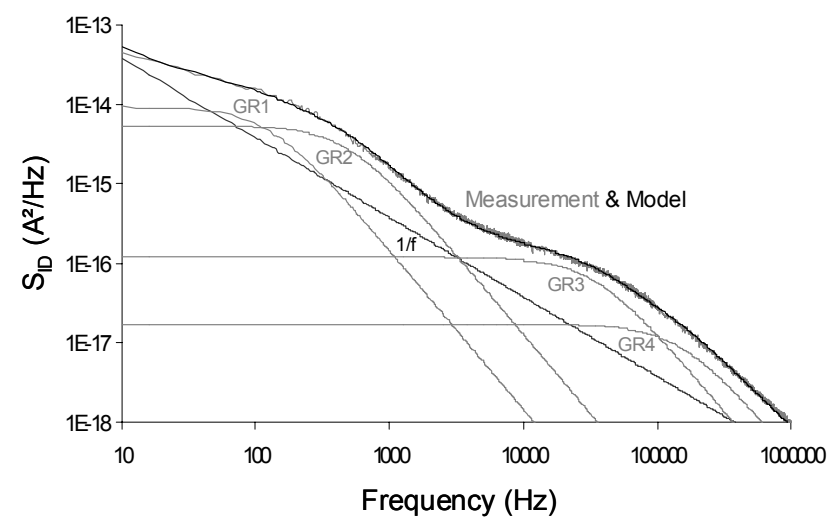

Figure. 6:.Extracted low frequency noise sources and overall spectrum $\left(0.25 \times 2 \times 75 \mu \mathrm{m}^{2}\right.$ HEMT @ $\left.V_{\mathrm{GS}}=-2 \mathrm{~V}, \mathrm{~V}_{\mathrm{DS}}=16 \mathrm{~V}\right)$

The measurement is performed in the $10 \mathrm{~Hz}-1 \mathrm{MHz}$ frequency range using the trans-impedance amplifier technique.

Figure 6 shows a typical noise spectrum that evidences the presence of numerous trapping-detrapping centers i.e. generation-generation (GR) phenomenon, and a flicker $1 / \mathrm{f}$ contribution. The closeness of the GR hinders their extraction. Analytical extraction procedure (using MatLab software) was developed to get the different contributions of the noise parameters.

\section{GAN HEMT MODEL}

The LFN and the dynamic S-parameters measurements are used to get the better compromise for the oscillator quiescent point, that is found at $\mathrm{V}_{\mathrm{GS}}=-3 \mathrm{~V}$ and $\mathrm{V}_{\mathrm{DS}}=10 \mathrm{~V}$.

\section{Pulsed measurements}

Pulsed measurement is performed under these 'hot' bias conditions to get the right output characteristics using a pulse length $\delta \mathrm{t}=0.1 \mu \mathrm{s}$ and a pulse separation $\mathrm{T}=0.5 \mathrm{~ms}$. Then the current source model is achieved using mathematical expressions based on Fager model [6] that is suited for the ohmic regime description of the device. Important care is brought to these analytical expressions being derivable up to three times at least to ensure the exactness of the controlled source model when used in harmonic balance simulation. The figure 7 illustrates the whole model.

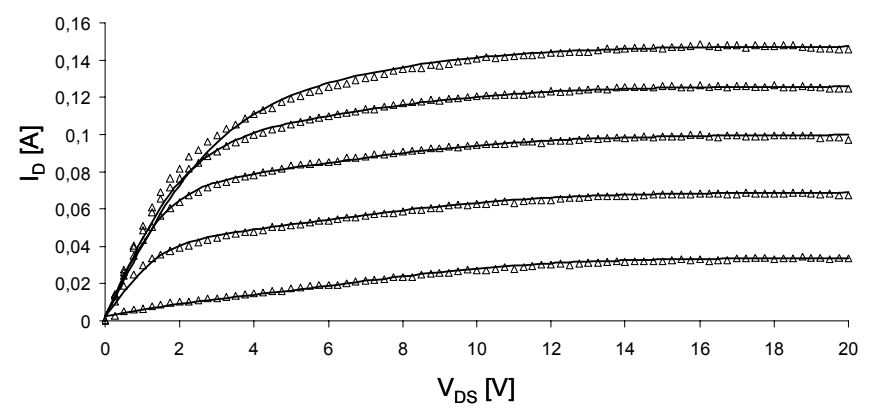

Figure 7: $0.25 \times 2 \times 75 \mu^{2}$ HEMT output pulsed characteristics $(\delta \mathrm{t}=0.1 \mu \mathrm{s}, \mathrm{T}=0.5 \mathrm{~ms})$ for gate-source voltage varying from $\mathrm{V}_{\mathrm{GS}}=0 \mathrm{~V}$ to $V_{G S}=-4 \mathrm{~V}$ (Bias condition: $V_{G S}=-3 \mathrm{~V}, V_{D S}=10 \mathrm{~V}$, Measurement : $\Delta$ and Simulation:--)

\section{Parasitic elements}

The extrinsic parasitic elements (pad capacitances, series resistances and inductances) are evaluated using the method developed by Dambrine [14]. The drain and gate pad capacitances can be extracted from Y-parameters at a gate voltage below the pinch-off. Next, the parasitic resistances and inductances are extracted under positive $\mathrm{V}_{\mathrm{GS}}$ bias conditions $\left(\mathrm{V}_{\mathrm{GS}}=+3 \mathrm{~V}\right)$ where the capacitances do not influence on the extraction. The small-signal model gives accurate results for $I_{D}$ ranging from $20 \mathrm{~mA}\left(@ \mathrm{~V}_{\mathrm{GS}}=-4 \mathrm{~V}\right)$ to $100 \mathrm{~mA}\left(@ \mathrm{~V}_{\mathrm{GS}}=0 \mathrm{~V}\right)$.

An illustration is given on figure 8 . 


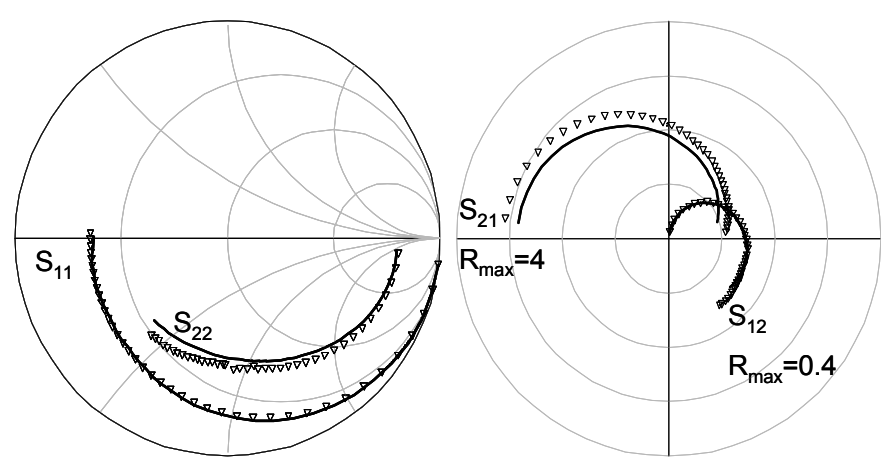

Figure. 8: $0.25 \times 2 \times 75 \mu \mathrm{m}^{2}$ HEMT S-parameters from $40 \mathrm{MHz}$ to $40 \mathrm{GHz}\left(\mathrm{V}_{\mathrm{GS}}=-3 \mathrm{~V} \mathrm{~V}_{\mathrm{DS}}=10 \mathrm{~V}\right.$, Measurements: $\Delta$; Simulation: - )

\section{1 tone compression}

The figure 9 shows the large signal device excursion behavior from the 'hot' quiescent point. The 1 tone compression of the transistor is in good agreement with experience. The output power $\mathrm{P}_{\mathrm{OUT}}$ is plotted versus the input power $\mathrm{P}_{\mathrm{IN}}$ for a HEMT featuring $0.25 * 2 * 75 \mu \mathrm{m}^{2}$ HEMT. The compression occurs for an output power at $\mathrm{P}_{1 \mathrm{~dB}}=19 \mathrm{dBm}$.

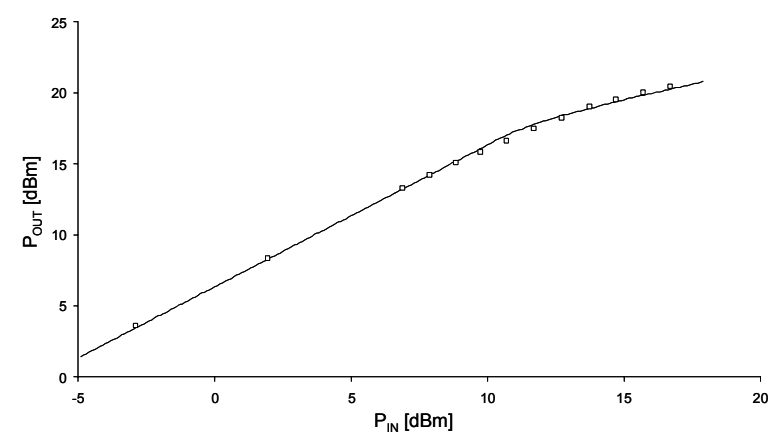

Figure. 9: $\mathbf{P}_{\text {OUT }}$ vs $P_{\text {IN }}(@ 10$ GHz); Measurement: $\square$;

Simulation :- -

\section{$X$ BAND OSCILLATOR USING A GAN HEMT}

This section is focused on the design of an X-Band oscillator using microwave integrated circuit technology.

Low phase noise oscillators are an important sub system for modern microwave communications. The reduction of phase noise increases the sensitivity of the system and reduced bit errors.

\section{MIC oscillator circuit}

The MIC circuit makes use of microstrip lines on cuflon substrate $\left(\varepsilon_{\mathrm{R}}=2.1, \tan (\delta)=4.5^{*} 10^{-3}\right)$. A common-source oscillator structure is designed with an open microstrip line for the resonator on the gate. Bonding wires are used to connect the transistor accesses to the microstrip lines. The starting oscillation conditions in this common-source configuration are obtained thanks to the negative resistance on the gate $\left(\mathrm{S}_{11}\right)$. However when the $S_{11}$ gain is maximal an undesirable negative resistance also appears due to the bonding wire inductances. By shifting the oscillation conditions towards a lower $\mathrm{S}_{11}$ gain zone (figure 7), $\mathrm{S}_{22}$ can be adjusted to a value below one.

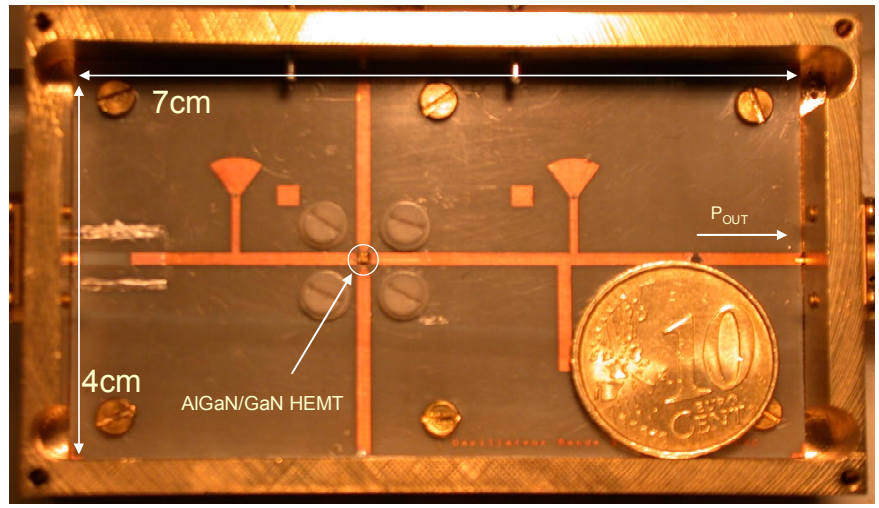

Figure 10: Hybrid oscillator LAAS-CNRS/RNRT project "ANDRO"

\section{Oscillator performances}

Oscillators based on HEMT GaN demonstrate that the phase noise performance $(-105 \mathrm{dBc} / \mathrm{Hz})$ is close to the state of the art for field effect III-V technology. Moreover the output power $(20 \mathrm{dBm})$ with $\mathrm{AlGaN} / \mathrm{GaN}$ HEMT is higher than the one with GaAs technology.

Our hybrid realization demonstrates also performances close to MMIC GaN oscillator [15].

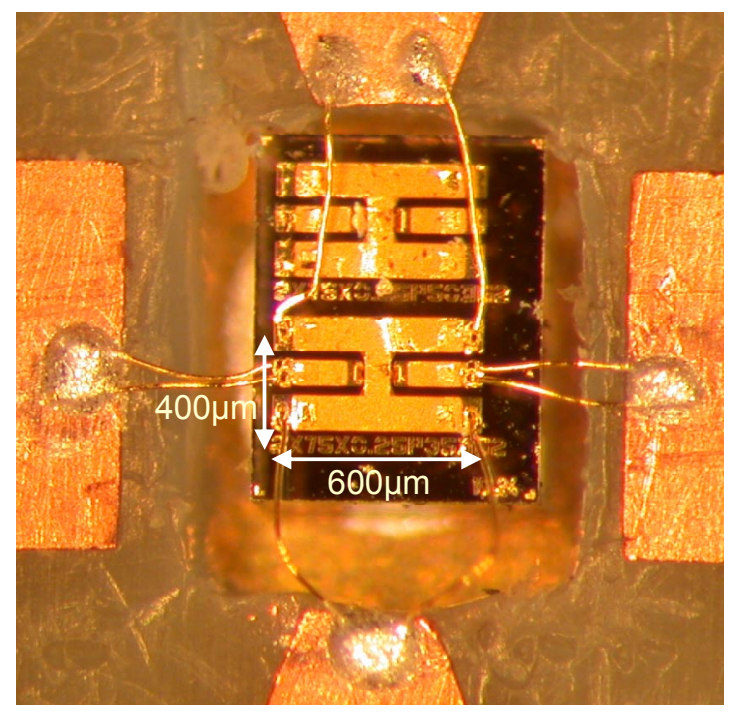

Figure 11: Thales TRT Tiger AlGaN/GaN HEMT 


\section{CONCLUSION}

$\mathrm{GaN}$ technology is very promising for the design of robust RF high power electronic modules. The inner immunity to electromagnetic aggressions reduces the architecture complexity, and enhances the performances, the integration level and the overall power management. Moreover, these wide band-gap technologies are well suited for reliable systems because of the excellent aptitude to withstand high temperatures (biasing and/or storage). Thus GaN circuits stand as a first choice technology that meets all requirements related to robust, low noise and high power modules dedicated to aeronautic subsystems.

Moreover, in future electronic systems, it should be interesting to remove electronic cables (easier and faster maintenance of electronic modules with a reduced number of connection cables): In board communications with flight controllers and commands should take benefit of remote-control transceivers using this $\mathrm{GaN}$ technology (robust against electromagnetic aggressions).

\section{ACKNOWLEDGMENTS}

This work is supported by the French Ministry of Research under RNRT's financial project (ANDRO). The authors specially want to thank Picogiga International Company and CRHEA (CNRS laboratory) for providing the devices.

\section{REFERENCES}

[1] A. Minko et al., "AlGaN-GaN HEMTs on Si with power density performance of $1.9 \mathrm{~W} / \mathrm{mm}$ at $10 \mathrm{GHz}$ ", IEEE Trans. Electron Device Lett., Vol. 25, N7, pp.453-455, July 2004..

[2] F. Van Raay, et al., "A Microstrip X-Band AlGaN/GaN Power Amplifier MMIC on s.i. SiC Substrate", $13^{\text {th }}$ GaAs Symposium Paris 2005 pp. 233-235

[3] www.Ltech-microwave.com/semiconducteurs.htm and www.rfhic.com/ttm/prod/pdf

[4] D. Krausse, et al., "Robust GaN HEMT low noise amplifier MMIC for X band application", $12^{\text {th }}$ GaAs Symposium Amsterdam 2004

[5] G. Soubercaze-Pun et al., "Design of a X-band GaN oscillator: from the low frequency noise device characterization and large signal modeling to circuit design" MTT-S 2006

[6] H. Ueda et al., "High current operation of $\mathrm{GaN}$ power HEMTs" Proceedings of the $17^{\text {th }}$ International Symposium on Power Semiconductor Devices \& IC's May 23-26,2005 Santa Barbara, CA [7] J.M. Peransin et al., "1/f noise in MODFET's at low drain bias" IEEE Trans. on Electron Devices, vol. 37, No 10, October 1990, pp. 2250-2253

[8] A.Balandin et al, "Low flicker-noise GaN/AlGaN heterostructure field effect transistor for microwave communications" IEEE Trans. On Microwave Theory and Technique, Vol. 47, No8, pp. 1413-1417, August 1999

[9] S.A Vitusevich et al, "Excess low frequency noise in AlGaN/GaN based high electron mobility tranistor" App.Physics.Lett Vol. 80, $N^{\circ} 12$, March 2002
[10] A.Balandin "Flicker noise in GaN/A10,15Ga0,85 N doped channel heterostructure field effect transistor" IEEE Electron Device Lett, Vol 19, pp 475-477 Dec 1998

[11] S.Rumyantsev "Low $1 /$ f noise in AlGaN/GaN HFET on SiC substrate" Phys.Stat.Sol 176,201 (1999)

[12] M.E Levinshtein "AlGaN/GaN high electron mobility field effect transistor with low 1/f noise" App.Phys.Lett,Vol 73, $N^{\circ} 8, p 1089$ (1998)

[13] D.Pavlidis "AlGaN/GaN high electron mobility transistor (HEMT) reliability" $13^{\text {th }}$ GaAs Symposium Paris 2005

[14] G. Dambrine et al., "A new method for determining the fET small-signal equivalent circuit" IEEE Trans. On Microwave Theory and Technique, Vol. 36, $N^{\circ} 7$, pp. 1151-1159, July 1988

[15] S.V Danylyuk "Phase noise study of AlGaN/GaN HEMT Xband oscillator" Phys.Stat.Sol N] 7,2615-2618 (2005) 